\title{
Revision Total Ankle Replacement
}

\author{
Mark S. Myerson, MD, Amiethab A. Aiyer, MD, and J. Kent Ellington, MD, MS \\ Based on an original article: J Bone Joint Surg Am. 2013 Dec 4;95(23):2112-8.
}

\section{Introduction}

The technique for revision total ankle replacement described in this article addresses the subsidence and loosening that occur when an Agility total ankle replacement fails.

The rates of success and failure of primary total ankle replacement have varied. Multiple studies have indicated failure rates of $10 \%$ to $30 \%$ over the course of ten years ${ }^{1-6}$. A recent meta-analysis of 317 total ankle replacements showed a failure rate of $12 \%$ at six years ${ }^{6}$. In another meta-analysis, of ten studies that included a total of 852 patients who had undergone total ankle replacement, $38 \%$ of the patients had an excellent result, $30.5 \%$ had a good result, $5.5 \%$ had a fair result, and $24 \%$ had a poor result ${ }^{7}$. The five-year survivorship rate was $78 \%$, and the ten-year rate was $77 \%$.

One of the challenges with salvage of failed total ankle replacements is the lack of suitable prostheses. Because of this, conversion to arthrodesis or even amputation become treatment considerations. We describe our approach to a failed total ankle replacement with the goal of best salvaging the joint with a revision arthroplasty.

\section{Step 1: Indications and Contraindications}

The main indications for revision total ankle arthroplasty include loosening and subsidence of the talar component, with no limit to the extent of subsidence or loss of talar bone stock as neither precludes use of a revision system, particularly when a flat cut on the talus can be made.

- Gross dissolution of the talus has previously been considered a contraindication to revision total ankle replacement. However, the technique described here can manage gross dissolution, thereby avoiding an arthrodesis with a large structural allograft.

- Commonly, the talar component of the failed arthroplasty subsides posteriorly, leading to angulation and deformation of the remaining talus (Fig. 1).

- Patients must have a good range of motion. It is imperative to obtain flexion and extension radio- graphs preoperatively to ensure that the range of motion is adequate (Fig. 2).

- Revision arthroplasty is contraindicated in patients who have either chronic pain or an infection (recent or ongoing). Furthermore, if the anterior soft-tissue envelope is severely scarred then the patient may not be an ideal candidate for a revision replacement. It is important to ascertain if the patient has had prior wound-healing issues in the anterior aspect of the ankle.

\section{Step 2: Anterior Incision and Joint Exposure}

Make the incision employing the prior anterior midline incision, create full-thickness flaps of tissue to diminish the risk of wound dehiscence, and completely expose and debride the joint as this is critical to revising the total ankle replacement correctly.

- With the patient in a supine position and a tourniquet applied, make the incision, incorporating the prior anterior midline incision.

- Identify and protect the medial dorsal cutaneous branch of the superficial peroneal nerve, which lies superficial to the extensor retinaculum and may be embedded in a scarred tissue bed from prior surgery.

- Identify the extensor retinaculum and incise it completely. Release it as distally as the proximal aspect of the talonavicular joint. Maintain thick flaps of the retinacular tissue for later repair. Do not open the tibialis anterior tendon sheath as bowstringing of the tendon could lead to woundhealing problems. Enter the interval between the tibialis anterior and the extensor hallucis longus tendons.

- Protect the deep neurovascular bundle.

- Limit retractor placement to avoid complications with wound-healing.

- Once the tibia is exposed, sharply incise the joint capsule over the ankle joint. Use an elevator to expose the joint medially and laterally. 
- There will be a substantial amount of heterotopic bone. Remove it from the anterior aspect of the joint until the prosthesis is completely visible (Fig. 3).

\section{Step 3: Remove the Talar Component and} Polyethylene

Remove the talar component, which is rarely difficult as it is usually loose.

- After adequate joint exposure has been obtained and heterotopic bone has been removed, extract the talar component.

- Place a curved 6-mm osteotome under the interface between the talus and the talar component. The osteotome should be able to lift the talar component off of the bone (Video 1).

- The talar component is often quite loose due to subsidence and osteolysis. Be careful not to gouge the talus with the osteotome.

- It may be helpful to insert the threaded insertion guide into the talar component to help facilitate removal.

- Once the talar component has been removed, extract the polyethylene. This is substantially easier after the talar component is out of the wound.

\section{Step 4: Remove the Tibial Component}

When removing the tibial component, it is critical to preserve as much of the anterior tibial cortex as possible to provide support for the revision tibial component.

- Once the talar component and the polyethylene have been removed, begin removing the tibial component by placing a small osteotome $(6 \mathrm{~mm}$ wide or smaller) at the interface between the tibial component and the tibial osseous cortex.

- Slowly disengage the tibial component from the osseous interface. This is a challenge when there is solid osseous ingrowth. Gradually maneuver the osteotome between the tibial component and the host bone to help loosen the component for removal. If the patient has an Agility total ankle replacement in place, be mindful of the medial-sided fin, which is often covered by 6 to $8 \mathrm{~mm}$ of anterior tibial bone (Video 2).

- Once the tibial component is loose, use a tamp to push the component out (Video 3).

- This technique preserves the majority of the anterior tibial cortical rim for support of the revision prosthesis.

\section{Step 5: Make the Tibial Bone Cut}

Tibial cuts can be made proximal or distal to tibial osseous defects.

- Making the tibial cut distal to osseous defects limits joint line elevation, but it must be assumed that the defects will be filled with bone graft or cement. This will facilitate preservation of as much bone as possible. The surgeon may choose to make a more proximal bone cut on the tibia, which removes osteolytic regions, but leads to joint line elevation.

- Insert a 3.5-mm guide pin bicortically into the proximal tibial tubercle in order to set mechanical alignment. Then attach the tibial alignment guide.

- Select the appropriately sized cutting guide. Attach the cutting guide to the tibial alignment jig

(Fig. 4). Make sure that the cut is perpendicular to the mechanical axis. Check the rotation of the guide as well prior to making the cut.

- Drill the proximal two holes on either side of the tibial cutting jig. Place pins in the proximal two holes to protect the malleoli from the excursion of the saw blade. Make the tibial cut (Fig. 5) and remove the cutting guide.

- Complete the vertical resection with an osteotome, following the template created by the two previously placed proximal pins.

\section{Step 6: Make the Talar Bone Cut}

It is preferable to use a cutting block for the talus that attaches to the tibial guide.

- In contrast to primary total ankle replacement systems, the talar component in a revision prosthesis is flat and enables a wider array of talar shapes and sizes. This accounts for the loss of bone and prior component subsidence.

- Attach the talar cutting block to the tibial alignment guide (Fig. 6).

- A limited amount of bone should be resected from the talus (Fig. 7). To facilitate this, slide the cutting block until it is flush with the talar surface. Positioning the talar cutting block in this way allows the talar cut to be made in the correct orientation with minimal resection of bone.

- Place pins to lock the talar cutting block into the desired position (Fig. 8), and place a saw through the distal slot of the guide to perform the talar cut.

- If it is not possible to use the talar cutting block, use a freehand technique to complete the cut on the talus (Fig. 9). 
- Place a lamina spreader into the wound to distract the joint. This aids with fluoroscopic visualization of the joint to ensure that the bone cuts and the joint preparation are adequate (Fig. 10).

- Evaluate the status of the osseous surfaces to ascertain whether grafting or cementing is necessary to support the revision components (Fig. 11).

\section{Step 7: Managing Loosening and Cavitary Defects}

If there is substantial bone loss around the tibia after component removal, consider impaction bone-grafting, as better bone quality makes it is easier to obtain a press fit and allow immediate weight-bearing.

- Loosening of the tibial or talar components is not a contraindication to revision total ankle replacement, but if there is substantial bone loss around the tibia after component removal, consider impaction bone-grafting.

- Mix morselized cancellous autograft or cancellous allograft with demineralized bone matrix. Grind the mixture further by hand or with use of a bone miller.

- $\quad$ Fill the defects with the mixture. Use bone tamps to impact the graft into the defect, aiming to provide stable osseous support for the revision implant. This technique is referred to as impaction grafting (Videos 4 and 5).

- Alternatively, if the tibial defect is moderate and you prefer to allow immediate weight-bearing, you can use polymethylmethacrylate cement.

\section{Step 8: Place Trial Components}

Size the tibia and talus and subsequently insert the tibial and talar trials and polyethylene simultaneously.

- After osseous defects have been grafted, use tibial and talar sizers.

- Insert the tibial and talar trials and appropriately sized polyethylene at the same time.

- Check that the ankle is appropriately balanced and whether further bone cuts are necessary.

- Once the components are appropriately positioned, lock the talar trial with pins placed medially and laterally on the anterior edge (Fig. 12). It is generally easier to prepare the tibia prior to the talus in the revision system.

- Check the fluoroscopic position of the trial components, and take the ankle through a complete range of motion to ascertain stability (Fig. 13).

- Drill holes for the tibial component keel and then remove the tibial trial.
- Drill holes for the talar component keel and then remove the talar trial.

- Thoroughly irrigate the wound.

\section{Step 9: Cementing Technique}

In revision settings, manual cement insertion is important because there is no medullary canal to work around.

- Insert cement in a doughy state before placing either the tibial or the talar component.

- Avoid using too much cement as this can lead to posterior extrusion and difficulty with extrusion. Posteriorly extruded cement is often irretrievable (Fig. 14).

- If a tibial defect is present, make sure that the tibial component is inserted in the correct orientation. Inadvertent compression of cement can lead to dorsiflexion of the prosthesis and development of an extension deformity.

\section{Results}

We previously reported the outcomes of revision of failed Agility total ankle replacements (DePuy, Warsaw, Indiana) in forty-one patients ${ }^{8}$. The mean time between total ankle replacement and revision arthroplasty was fifty-one months. The most common indication for revision total ankle replacement was talar subsidence (in twenty-six [63\%] of the forty-one patients). A subtalar arthrodesis was performed simultaneously in twentytwo patients $(54 \%)$, nineteen of whom had a customdesigned long-stem talar component used in the revision arthroplasty.

There was no significant difference in component position between the preoperative and postoperative radiographic evaluations. The arc of motion improved $5^{\circ}$, from $18^{\circ}$ preoperatively to $23^{\circ}$ postoperatively. The improvement was in plantar flexion.

Of the forty-one patients who underwent revision total ankle replacement, thirty-four retained the total ankle replacement. Five patients underwent a revision arthrodesis, and two patients had an amputation.

At the time of final follow-up, at a mean of 49.1 months, the American Orthopaedic Foot \& Ankle Society (AOFAS) score was 65 points, the Short Form-12 score was 93.5 points, the visual analog scale score for pain was 4.4 points, and the Revised Foot Function Index score was 137.9 points. Twenty-eight (68\%) of the forty-one patients reported a good or excellent result. Of these twenty-eight patients, twenty-four had retained the total ankle replacement, two had undergone a tibiotalocalcaneal arthrodesis, and two had undergone an amputation. While $73 \%$ of the patients were able to return to their prior job, only $44 \%$ were able to return to their previous activity level. The most important predictor 
of a poor outcome, based on the AOFAS hindfoot score, was the degree of preoperative talar subsidence.

\section{What to Watch For}

\section{Pitfalls \& Challenges}

- Many patients with a previously performed ankle replacement, particularly when the Agility prosthesis was used, have implants from the syndesmotic arthrodesis or in the medial malleolus. These screws should be left in place, especially in the medial malleolus, to prevent the bone from fracturing during implant placement (Fig. 15).

- The malleoli should be protected with provisional Kirschner wires to prevent fracture.

- Implants that cross the tibia should be removed to facilitate correct placement of the tibial component. Many of these screws will strip with attempted removal, and it is helpful to have a power tool available to cut through the screw prior to insertion of the trial tibial component (Fig. 16).

- Revision ankle arthrodesis after failure of a total ankle replacement is not straightforward. Loss of talar bone stock from component subsidence may necessitate the use of a structural allograft.

- Use of augments should be considered to help build up the talar component when there was substantial subsidence of the failed primary component. This should be completed to ensure that the component is as parallel to the ground as possible.

- Talar subsidence has been correlated with patient outcome and is an important consideration in either primary or revision arthroplasty.

- Positioning the revision tibial component in extension is often the function of a loss of anterior tibial bone during removal of implants used during the index arthroplasty. Regardless of bonegrafting and engagement of metaphyseal bone with stems, weakening of anterior distal tibial bone is a risk factor for migration of the revision tibial component.

- Careful monitoring for talar subsidence should be carried out after primary total ankle replacement; we recommend that treating surgeons act quickly if there is evidence of subsidence of the talar component.

- Patients should be informed that although goodto-excellent results can be achieved, fewer than half of patients return to previous activity levels ${ }^{8}$.

Mark S. Myerson, MD

Amiethab A. Aiyer, MD

Institute for Foot and Ankle Reconstruction at Mercy, 301 St. Paul Place, Baltimore, MD 21201. E-mail address for M.S. Myerson:

Mark4feet@aol.com. E-mail address for A.A. Aiyer: tabsaiyer@gmail.com

J. Kent Ellington, MD, MS

Foot and Ankle Institute, OrthoCarolina, 2001 Vail Avenue, Suite 200B, Charlotte, NC 28207. E-mail address: kentellingtonfx@gmail.com

Disclosure: None of the authors received payments or services, either directly or indirectly (i.e., via his or her institution), from a third party in support of any aspect of this work. One or more of the authors, or his or her institution, has had a financial relationship, in the thirty-six months prior to submission of this work, with an entity in the biomedical arena that could be perceived to influence or have the potential to influence what is written in this work. In addition, one or more of the authors has a patent or patents, planned, pending, or issued, that is broadly relevant to the work. No author has had any other relationships, or has engaged in any other activities, that could be perceived to influence or have the potential to influence what is written in this work. The complete Disclosures of Potential Conflicts of Interest submitted by authors are always provided with the online version of the article.

\section{References}

1. Knecht SI, Estin M, Callaghan JJ, Zimmerman MB, Alliman KJ, Alvine FG, Saltzman CL. The Agility total ankle arthroplasty. Seven to sixteen-year follow-up. J Bone Joint Surg Am. 2004 Jun;86(6):1161-71.

2. Karantana A, Hobson S, Dhar S. The Scandinavian Total Ankle Replacement: survivorship at 5 and 8 years comparable to other series. Clin Orthop Relat Res. 2010 Apr;468(4):951-7. Epub 2009 Jul 16.

3. Wood PL, Prem H, Sutton C. Total ankle replacement: medium-term results in 200 Scandinavian Total Ankle Replacements. J Bone Joint Surg Br. 2008 May;90(5):605-9.

4. Wood PL, Karski MT, Watmough P. Total ankle replacement: the results of 100 Mobility total ankle replacements. J Bone Joint Surg Br. 2010 Jul;92(7):958-62.

5. Henricson A, Skoog A, Carlsson A. The Swedish Ankle Arthroplasty Register: an analysis of 531 arthroplasties between 1993 and 2005. Acta Orthop. 2007 Oct;78(5):569-74. 
6. Besse JL, Colombier JA, Asencio J, Bonnin M, Gaudot F, Jarde O, Judet T, Maestro M, Lemrijse T, Leonardi C, Toullec E; l'AFCP. Total ankle arthroplasty in France. Orthop Traumatol Surg Res. 2010 May;96(3):291-303. Epub 2010 Apr 15.

7. Haddad SL, Coetzee JC, Estok R, Fahrbach K, Banel D, Nalysnyk L. Intermediate and long-term outcomes of total ankle arthroplasty and ankle arthrodesis. A systematic review of the literature. J Bone Joint Surg Am. 2007 Sep;89(9):1899-905.

8. Ellington JK, Gupta S, Myerson MS. Management of failures of total ankle replacement with the Agility total ankle arthroplasty. J Bone Joint Surg Am. 2013 Dec 4;95(23):2112-8.

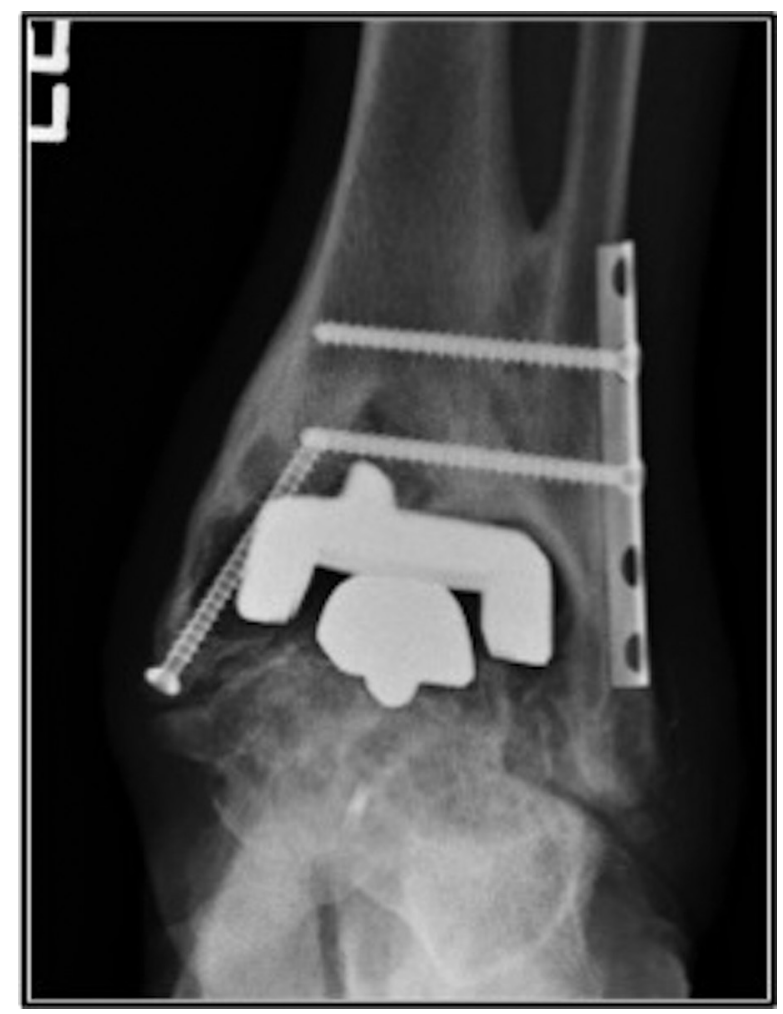

Fig. 1

The talar component often subsides posteriorly. This leads to angulation and deformation.

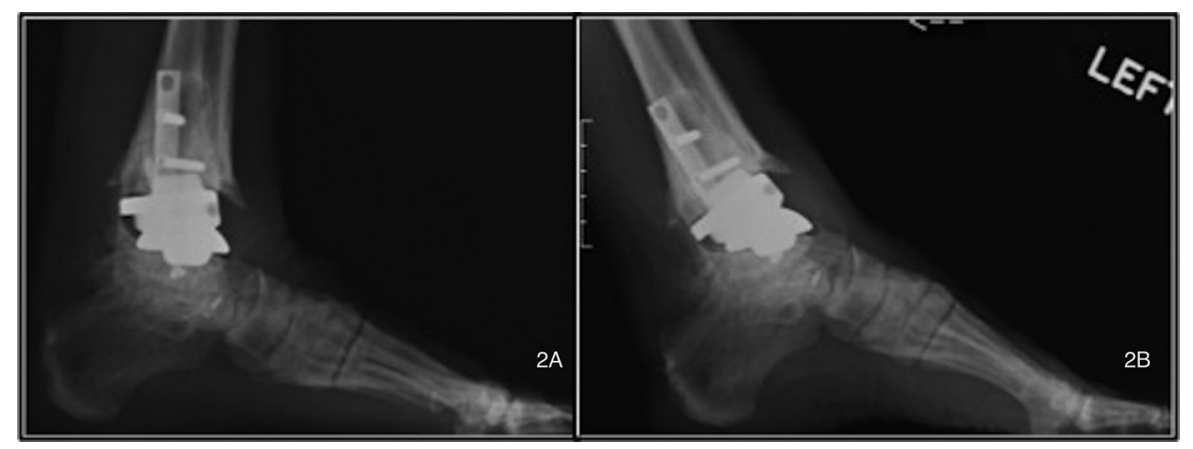

Fig. 2

The range of motion needs to be ascertained preoperatively with flexion and extension radiographs. 


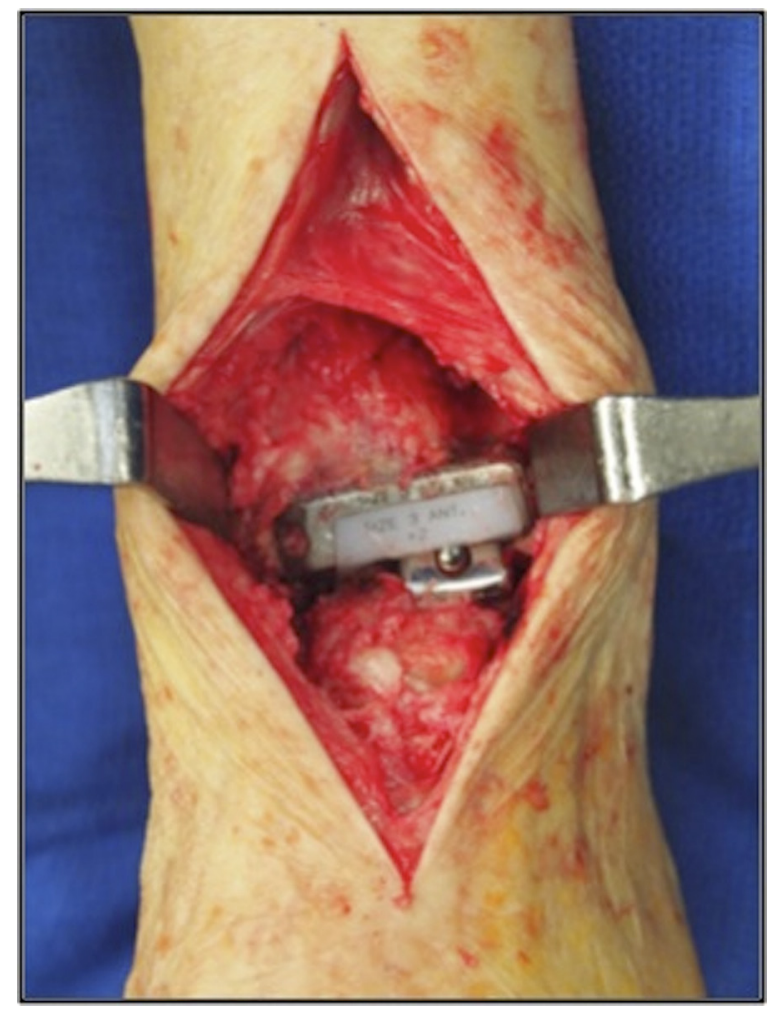

Fig. 3

All heterotopic bone needs to be removed from the anterior aspect of the joint until the prosthesis is completely visible.

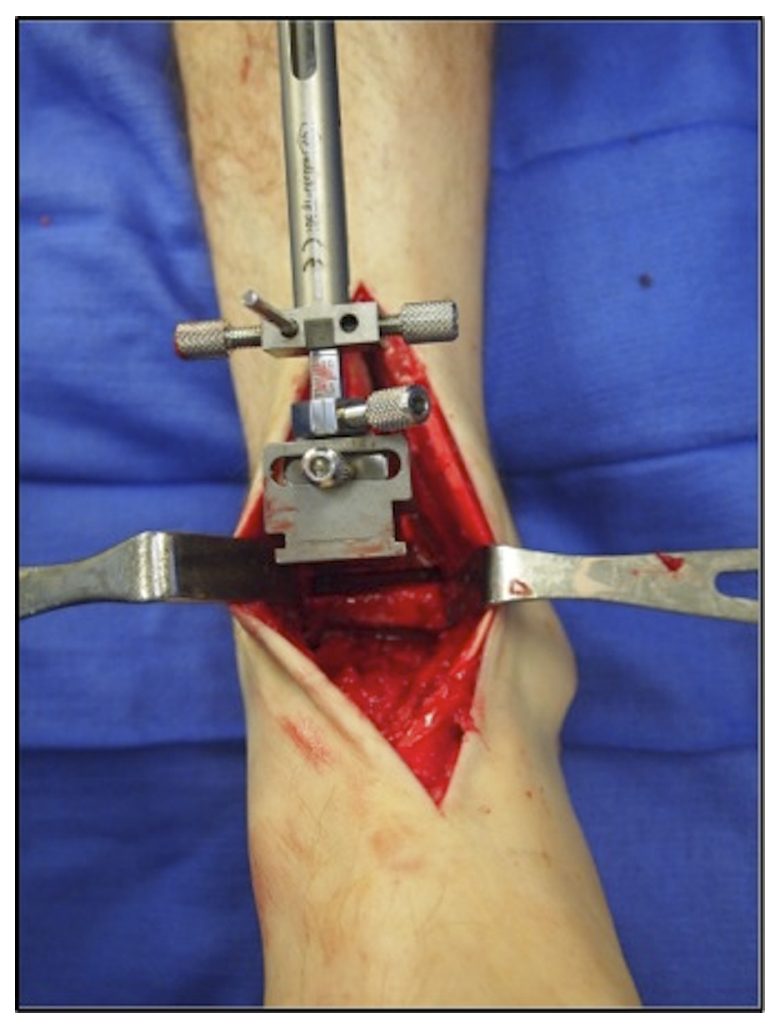

Fig. 5

Two proximal holes should be drilled on either side of the tibial cutting jig. Pins should be placed in these two holes to protect the malleoli from the excursion of the saw blade. The tibial cut should be made afterward.

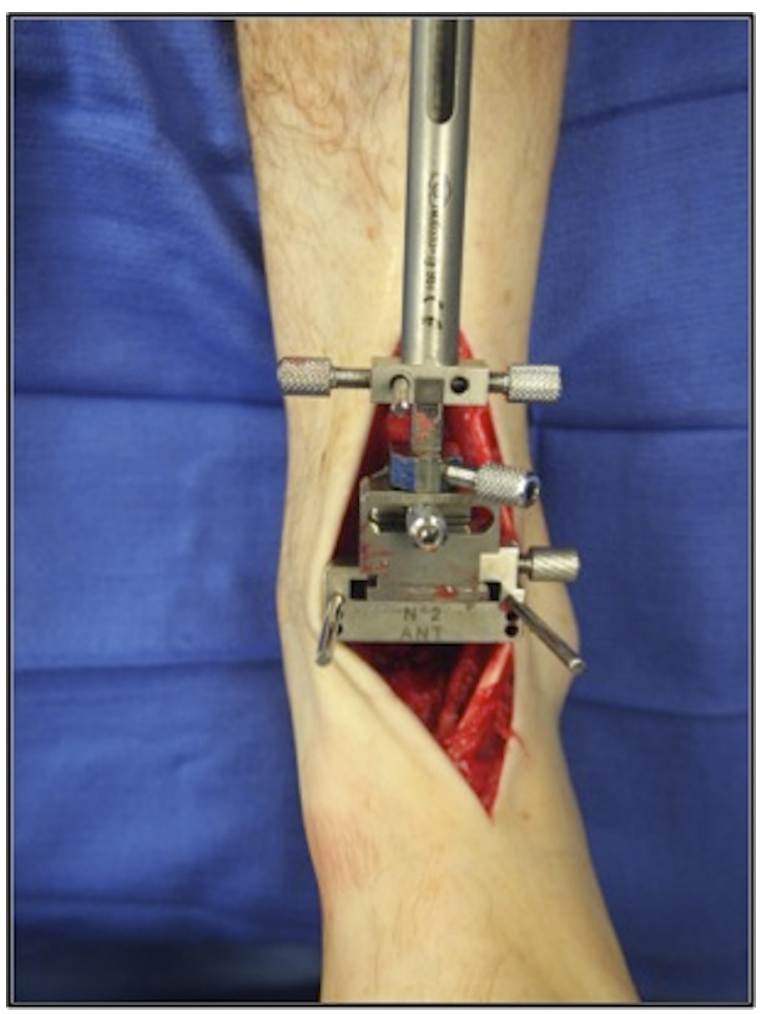

Fig. 4

The correctly sized cutting guide should be affixed to the tibial alignment jig. Check the rotational alignment; the cut should be perpendicular to the mechanical axis. 


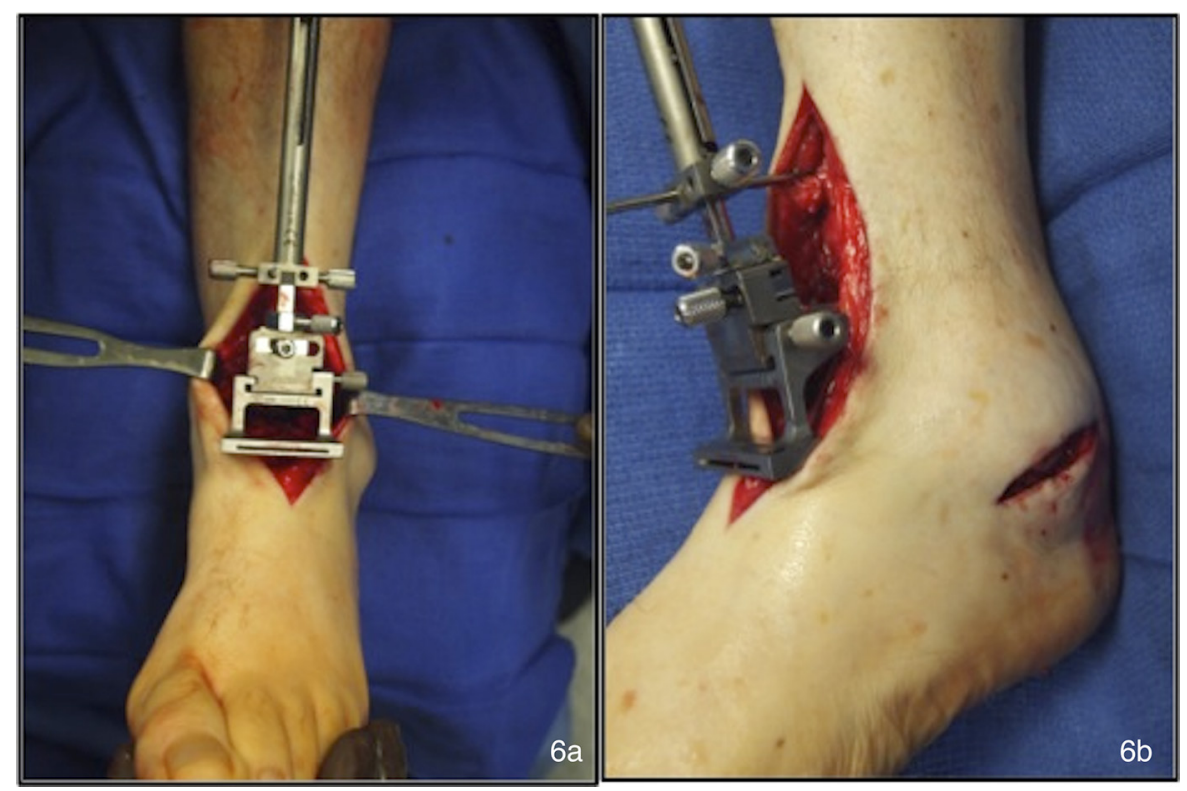

Fig. 6

The talar cutting block should be affixed to the tibial alignment guide.

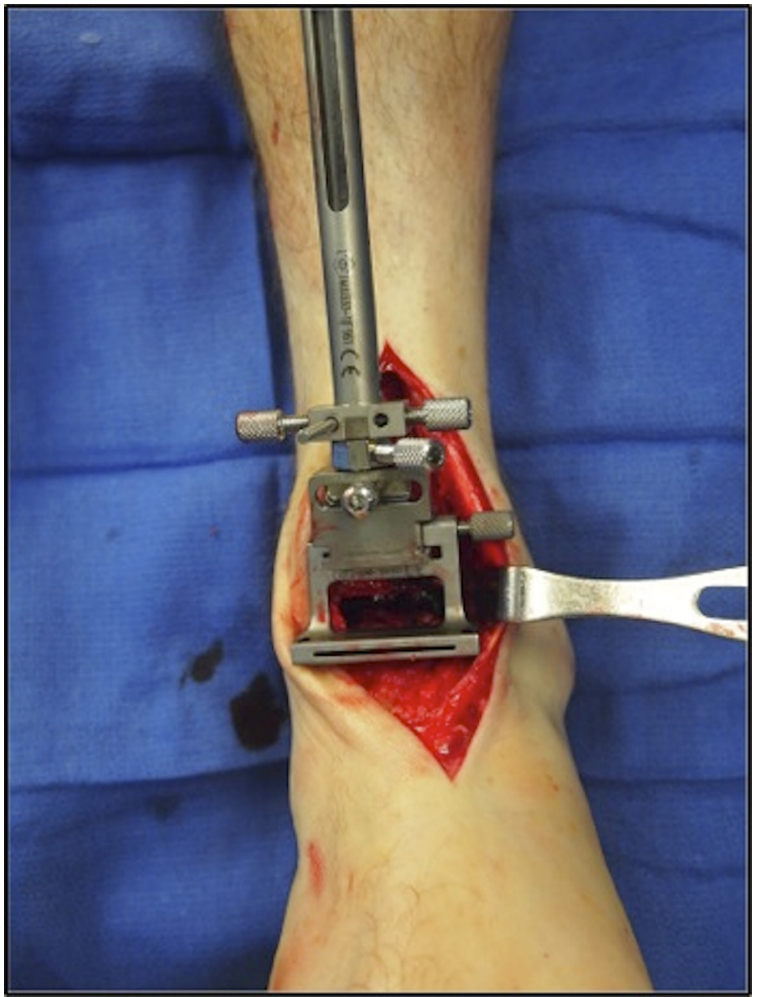

Fig. 7

The amount of bone that is resected from the talus should be limited.

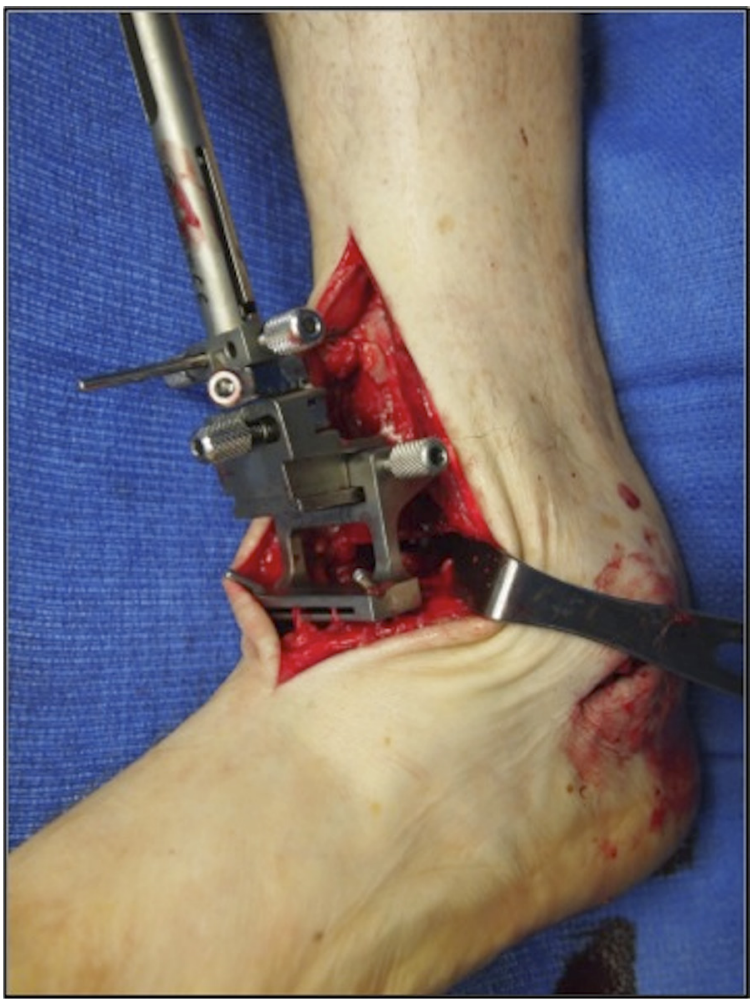

Fig. 8

The talar cutting block should be locked into position with pins. 


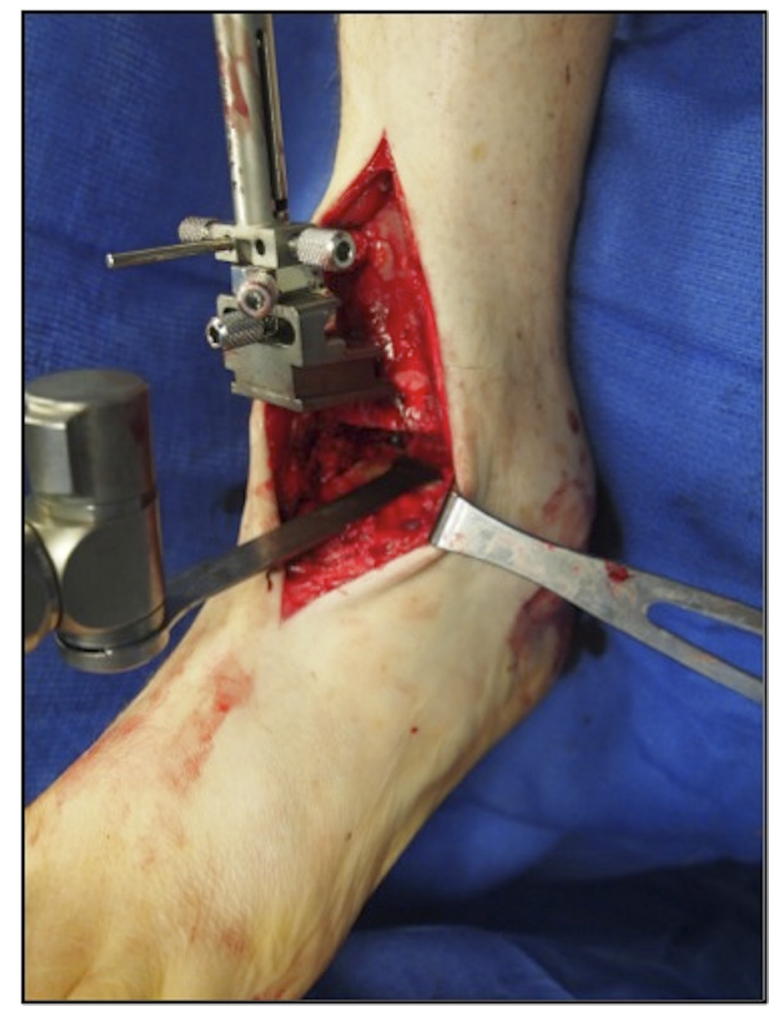

Fig. 9

If it is not possible to use a talar cutting block, a freehand cut can be completed on the talus.

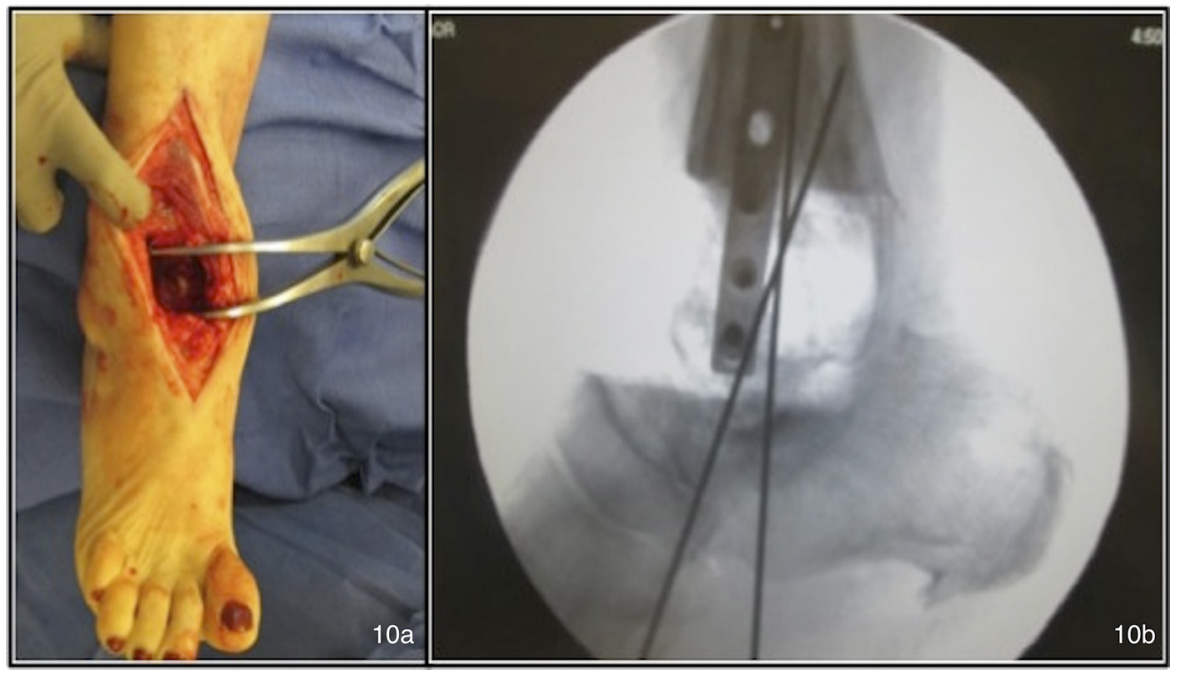

Fig. 10

A lamina spreader can be used to distract the joint to ensure the adequacy of the bone cuts and of the joint preparation. 


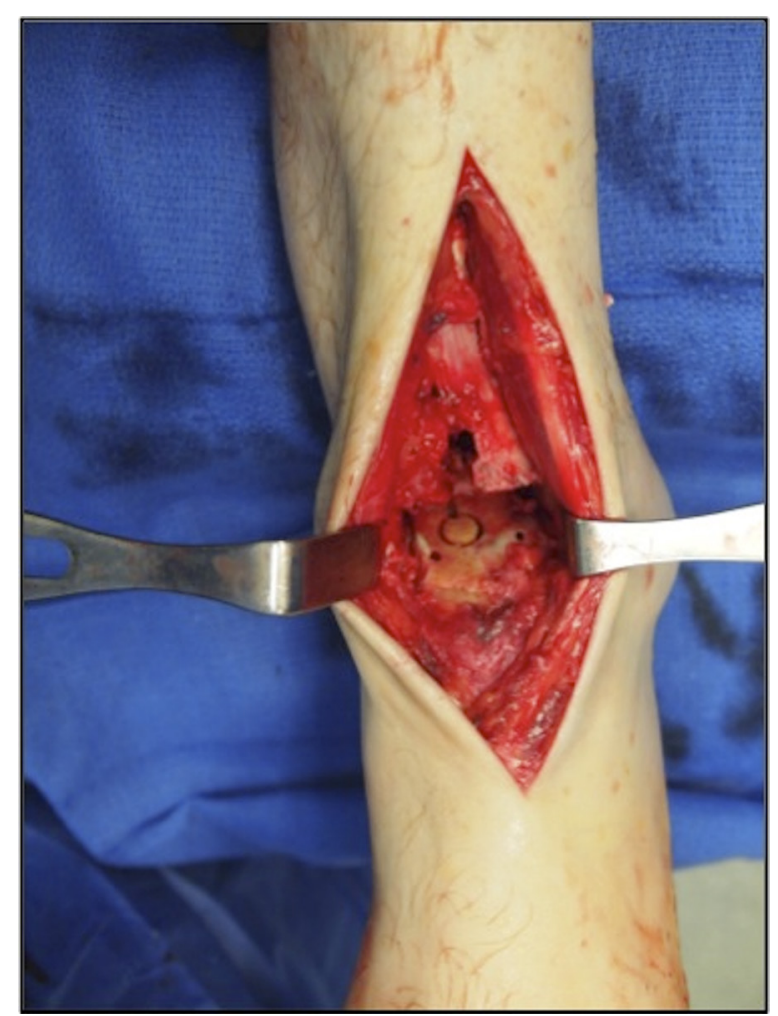

Fig. 11

The osseous surfaces should be evaluated to determine whether bone-grafting or cementing is necessary to support the revision components.

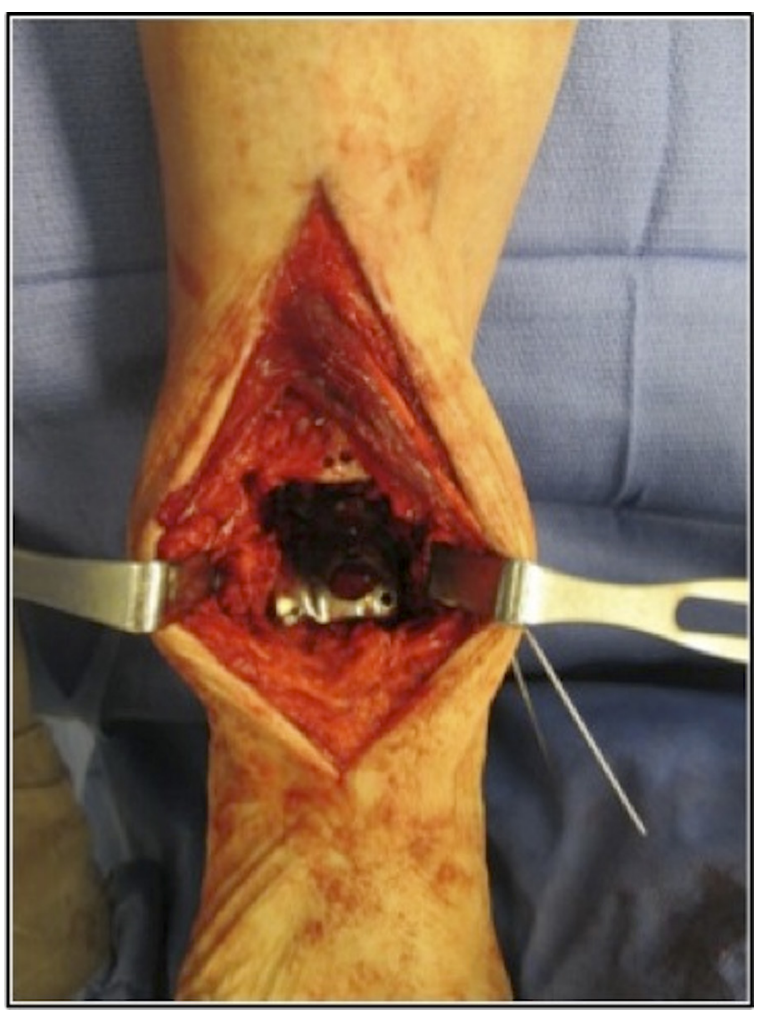

Fig. 12

Once the components are appropriately positioned, the talar trial is locked in place with pins placed medially and laterally. In the revision system, the tibia is prepared prior to the talus.

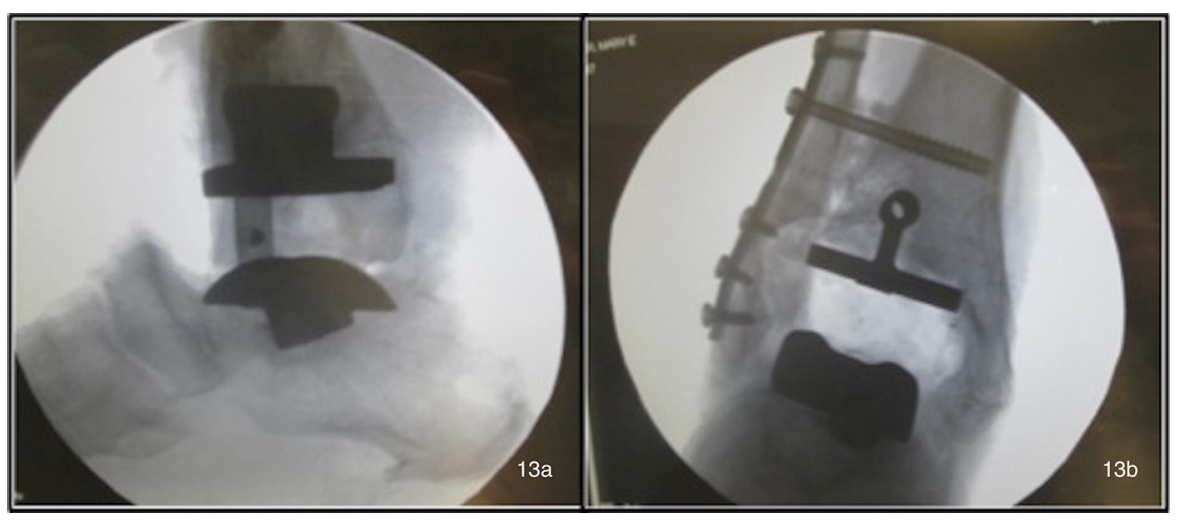

Fig. 13

Check the component position under fluoroscopy; the ankle should be checked for stability through the entire arc of motion. 


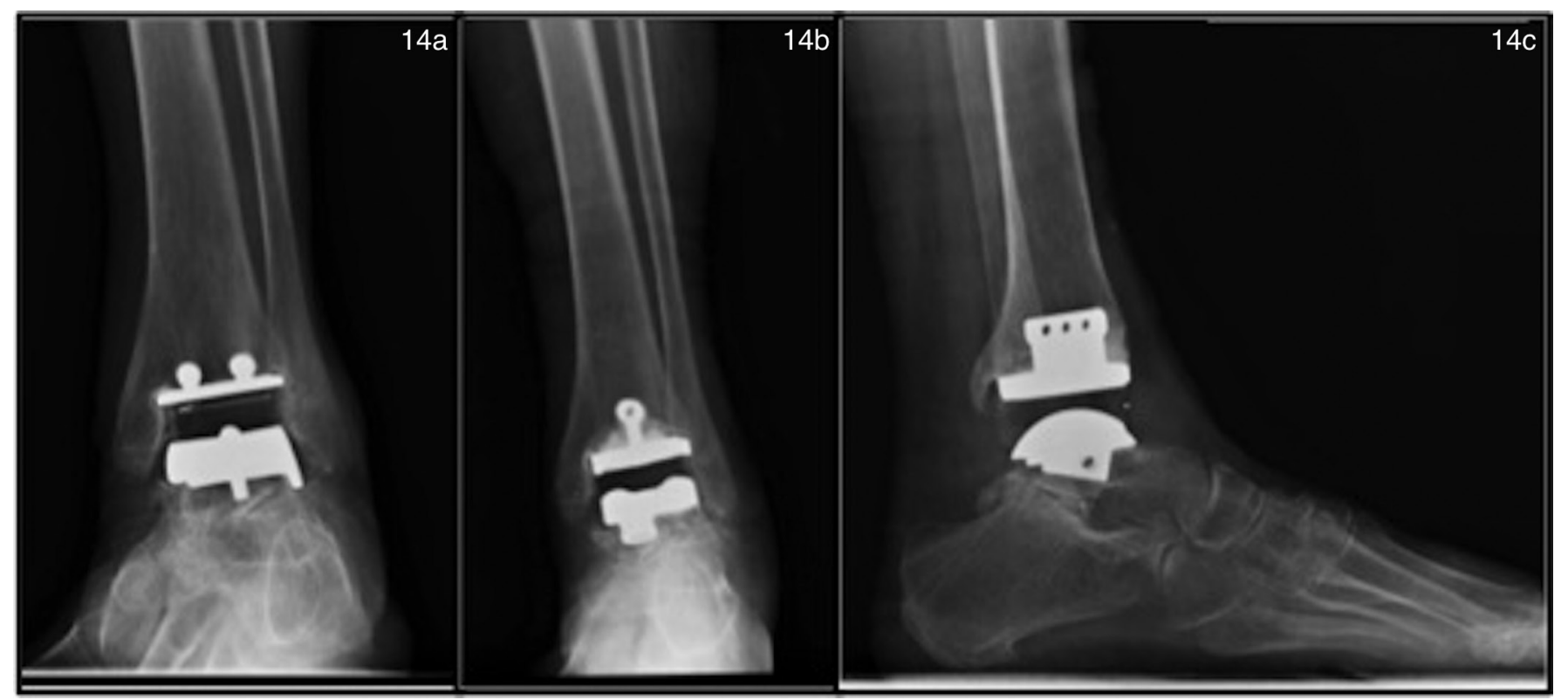

\section{Fig. 14}

Use of excess cement should be avoided. This can lead to posterior extrusion of the cement. Cement in this area is often irretrievable.

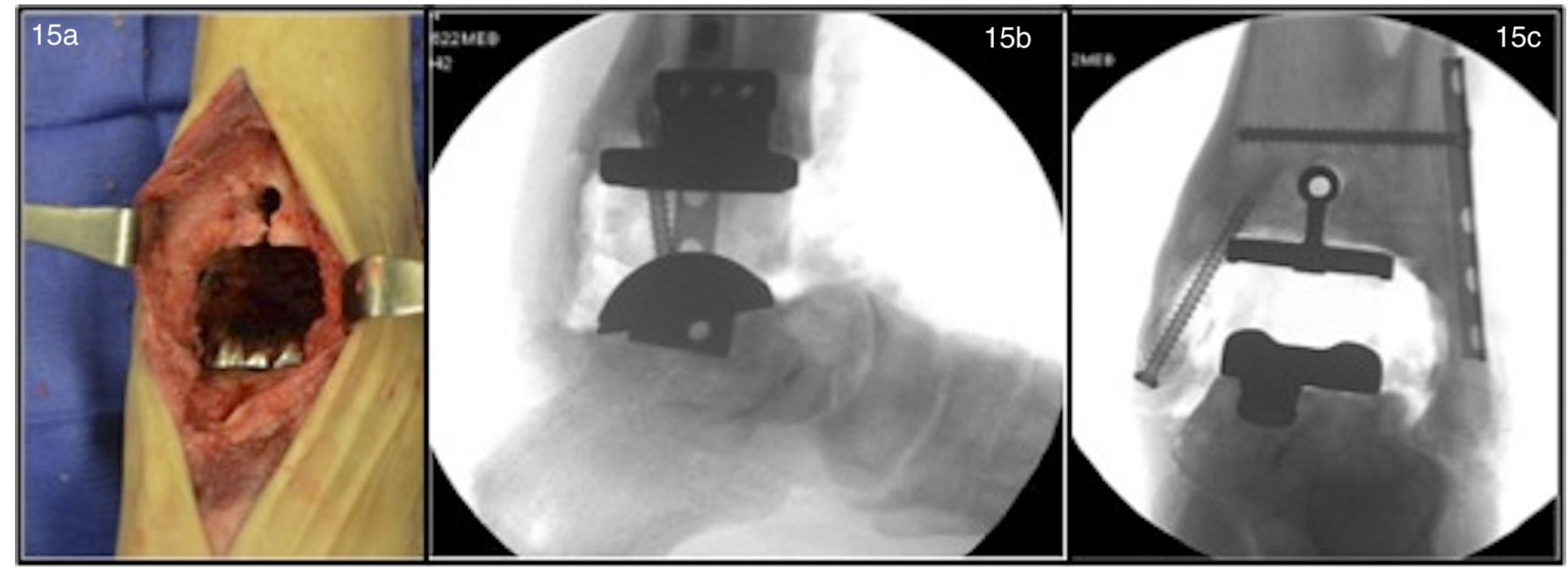

Fig. 15

Patients often have implants in place from previously performed ankle replacements. Implants in the medial malleolus should be left in place to prevent the bone from fracturing during implant placement. 


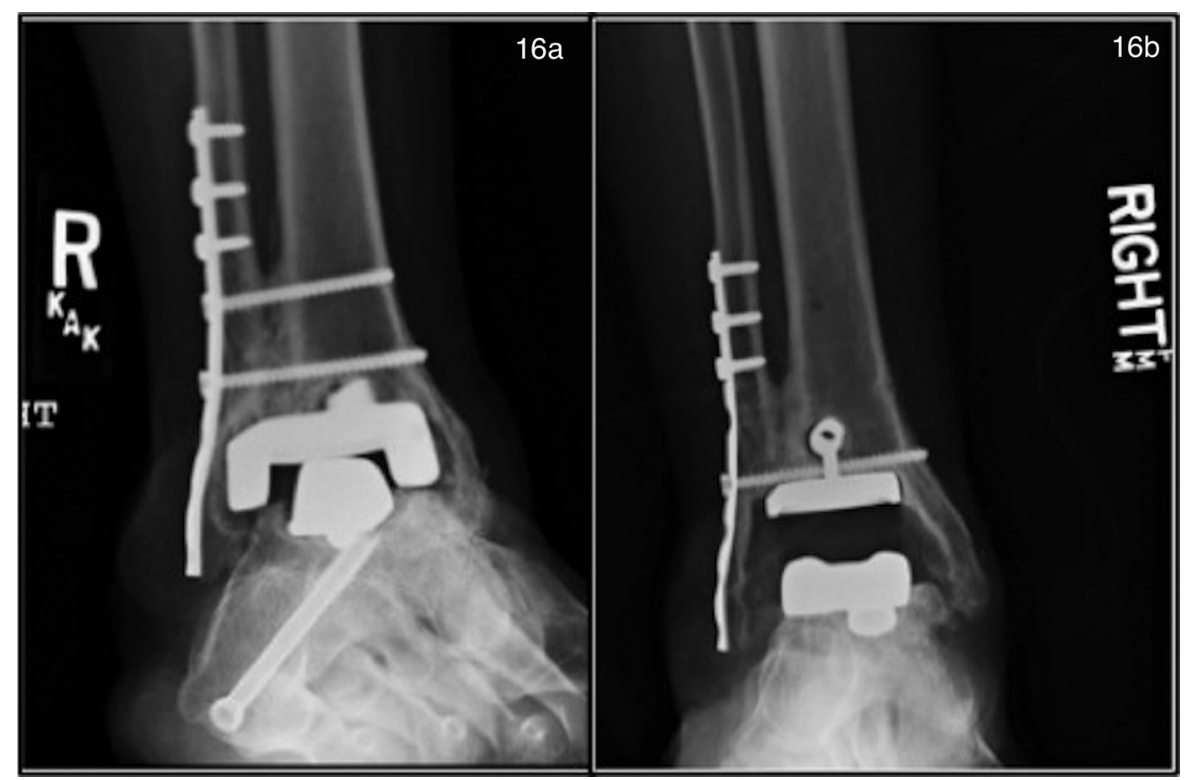

Fig. 16

Screws that are in place from a prior ankle replacement may strip when removal is attempted. It is wise to have a power tool available that facilitates screw extraction. 